
\title{
ПРОБЛЕМА АДАПТАЦИИ СОВРЕМЕННОГО СТУДЕНТА В ИНФОРМАЦИОННОМ ОБРАЗОВАТЕЛЬНОМ ПРОСТРАНСТВЕ
}

\section{THE PROBLEM OF ADAPTATION OF THE MODERN STUDENT IN THE INFORMATION EDUCATIONAL SPACE}

N. Volkova

Summary: The article deals with the problem of adaptation of the modern student in the information educational space. The relevance of the work is due to the fact that in higher education, the transformation associated with the active development of information and computer technologies reflects the social demand, requiring teachers and students as subjects of the modern information society to immediately adapt to the constantly changing conditions of life and professional activity. The author gives the opinions of modern scientists about the importance of computerization of higher education, as well as gives an overview of the most striking problems associated with the adaptation of a modern student in the information educational space. The priority of computer technologies for modern people, especially for the younger generation, which is maximally immersed in computer reality. Virtual reality for students of higher educational institutions is an integral part of daily life, leisure, as well as educational and even scientific activities. The most important task of education is to develop the principles of organizing a whole information space, where knowledge with the help of technical means can be available to all participants in various areas of pedagogical activity, from educational to expert, from research to organizational and managerial. As a result, it is concluded that taking into account the research of modern authors, it is possible to note the fundamental importance of changing human adaptation in the new information environment. The peculiarities of this environment stimulate the adjustment of existing mechanisms of socio-cultural and natural human development, as well as contribute to the development of new ones. Becoming the core of civilization, modern information technologies can change a person's life, its quality and especially its content.

Keywords: adaptation, information and educational space, computerization, virtual reality, information and computer technologies, information society.
И нформационно-технический научный прогресс привел к появлению инноваций, сокращающих и удешевляющих процесс управления различными социальными системами. К ним традиционно причисляют уже привычные телефон, радио и телевидение, однако, в последние годы все большее значение приобретают компьютеры и Интернет. Перемены в социальном и экономическом аспектах жизни общества приводят к усилению роли информации, следовательно, к постоянному совершенствованию системы, обеспечивающей ее
Волкова Нина Петровна

к.ф.н., дочент, Московский Авиационный Институт (национальный исследовательский университет) petrovnavolkova@mail.ru

Аннотация: В статье рассматривается проблема адаптации современного студента в информационном образовательном пространстве. Актуальность работы обусловлена тем, что в высшем образовании трансформация, связанная с активным развитием информационных и компьютерных технологий, отражает социальный запрос, требуя от преподавателей и студентов как субъектов современного информационного общества немедленной адаптации к постоянно меняющимся условиям жизни и профессиональной деятельности. Автор приводит мнения современных ученых о важности компьютеризации высшего образования, а так же дает обзор наиболее ярких проблем, связанных с адаптацией современного студента в информационном образовательном пространстве. Приоритетность компьютерных технологий для современного человека, особенно для молодого поколения, которое максимально погружено в компьютерную действительность. Виртуальная реальность для студентов высших учебных заведений - неотъемлемая часть ежедневного быта, досуга, а также учебной и даже научной деятельности. Важнейшей задачей образования является выработка принципов упорядочивания цельного информационного пространства, где знания при помощи технических средств смогут быть доступны всем участникам различных направлений педагогической активности, от учебной до экспертной, от научно-исследовательской до организационной и управленческой. В результате делается вывод, что учитывая исследования современных авторов, можно отметить фундаментальную важность изменения адаптации человека в новой информационной среде. Особенности этой среды стимулируют корректировки существующих механизмов социокультурного и природного развития человека, а также способствуют выработке новых. Становясь стержнем цивилизации, современные инфотехнологии способны изменить жизнь человека, ее качество и особенно - содержание.

Ключевые слова: адаптация, информационно-образовательное пространство, компьютеризация, виртуальная реальность, информационные и компьютерные технологии, информационное общество. менеджмент. Достижения науки и техники и новейшие разработки продвигают информацию в качестве основного фактора, влияющего на производственные процессы как в отношении техники и ее функционирования, так и в качестве повышения квалификации работников. Успешность организации процесса управления невозможна без хорошо организованного и налаженного информационного развития.

В высшем образовании подобная трансформация от- 
ражает социальный запрос, требуя от преподавателей и студентов как субъектов современного информационного общества немедленной адаптации к постоянно меняющимся условиям жизни и профессиональной деятельности [12. С.385].

К сожалению, исследования на такие важные в образовательной сфере темы как связь обучения с информационными технологиями, крайне малочисленны. Актуальными на сегодняшний день являются следующие вопросы: адаптация использования технологий обучающимися в свете их когнитивных данных, а также выработка последующих стратегий обучения на этой основе, принципы успешного и неуспешного освоения технологических новшеств, а также тема воздействия информации и ее усвоения при использовании электронных носителей на усвоение учебного материала.

Общественное развитие неразрывно связано с системой образования. Подготовка квалифицированных профессионалов в высшей школе заключается в формировании устойчивых компетенций, что подразумевает для обучающегося не только усвоение переданных знаний, формирование навыков и умений, но и саморазвитие. Современный студент, выходя из стен вуза, должен понимать, что теперь его задача - самообучаться на протяжении всей жизни, что позволит не просто применять знания, полученные от преподавателей, но и самостоятельно искать новые решения в профессии, изучая опыт коллег и приходя к собственным выводам. Использование информации в данном контексте особенно важно. Кроме этого, уже на этапе студенчества будущий выпускник должен понимать основные принципы работы с информацией, ее безопасное и экологичное использование в рамках современного цивилизованного общества. Осознав ответственность за получение, обработку информации, обучающийся не только постигает принципы использования технических средств, но и принимает ответственность за полученные данные и действия с ними, в том числе касающиеся сохранения и защиты государственной тайны. Важно дать студентам четкое понимание ситуации - информационное пространство создает, потребляет и перемещает информацию, которая необходима для дальнейшего развития общества [8]. Важнейшей задачей образования является выработка принципов упорядочивания цельного информационного пространства, где знания при помощи технических средств смогут быть доступны всем участникам различных направлений педагогической активности, от учебной до экспертной, от научно-исследовательской до организационной и управленческой. Подобное пространство следует рассматривать в нескольких аспектах:

- повышение качества и эффективности образовательного процесса;

- обеспечение базового и дополнительного качественного образования для взрослых;
- интенсификация процесса научных изысканий в рамках вузов;

- интегрирование в мировую сеть национальных образовательных систем, что расширит количество полезного материала и обеспечит международный доступ к разработкам отдельных стран;

- повышение результативности системы образования и ее отдельных частей - образовательных учреждений [10. C.45.].

Исследуя данную проблематику, Д.Д. Калимуллин обозначает приоритетность компьютерных технологий для современного человека, особенно для молодого поколения, которое максимально погружено в компьютерную действительность. Виртуальная реальность для них - неотъемлемая часть ежедневного быта, досуга, а также учебной и даже научной деятельности [5. С. 255]. Это наблюдение подтверждает и другой автор: в ходе изучения мотивационной парадигмы студентов в процессе работы с информационными продуктами и технологиями, отмечая создание и принятие позитивного отношения к компьютеру как средству обучения и профессиональной деятельности, а также формирование мотивационно-смыслового паттерна, заключающегося в положительной оценке и доверии к информационнокоммуникационным инновациям [11. С.118].

Однако во многих исследованиях проявляется обеспокоенность темой дезадаптации человека в ходе освоения технологий, что подчеркивает необходимость проведения дополнительных социальных исследований и учета биологических изменений человека во время существования в информационном пространстве. Возникновение информационного стресса может быть незаметным и неярким, но иметь характерную для нервно-психических заболеваний симптоматику, которая приводит к заметным замедлениям в обучении, социальном развитии, а также может повлиять на всю техносферу, проявляясь в росте числа чрезвычайных ситуаций, поскольку человек как оператор технических систем может быть ненадежен [9. С. 178].

В подобных новых информационных условиях человек может более полно реализовать свой творческий потенциал, однако, необходимо сделать акцент на появлении особых требований к развитию и саморазвитию. Исследуя изменения в социально-культурной сфере, происходящую адаптацию к информационному устройству новейшей общественной среды, необходимо анализировать все факторы, влияющие на формирование так называемого цивилизованного человека как новейшего из типов личности [1. С. 60].

Современный человек адаптирует информацию с некоторыми особенностями, основные аспекты которых необходимо упомянуть. Социальные структуры форми- 
руются по принципам идентичности. На фоне развития информационного мира проблема экологии человека приобретает особую актуальность. Увеличивается количество аудиовизуальных способов передачи любой информации, что приводит к стереотипизации массовой культуры и, соответственно, массового сознания.

С морально-этической стороны в адаптации человека к современному инфополю есть несколько проблем:

- сомнения в достоверности получаемой информации;

- трудность определения первоисточника;

- границы самоидентификации становятся шире и прозрачнее, что делает общение личностно неопределенным (ярким примером данного аспекта является использование «смайлов» в качестве неформальной формы коммуникации);

- анонимность, нередко влекущая за собой агрессию и вседозволенность в общении [6. С. 37].

Необходимо отметить, что на поведение и ценности современной личности информация оказывает решающее влияние. Компьютерные технологии и перенасыщение ими в жизни может привести к переменам в социальной адаптации личности. В высшем профессиональном образовании широкое применение технологий обнажает еще одну проблему - обесценивание доступной информации. Сталкиваясь с большим количеством данных, получаемых при помощи компьютерных технологий, обучающийся вынужден разбираться с ними самостоятельно, что зачастую оказывается трудной задачей. Информацию по предмету изучения сложно сортировать и отфильтровать по степени значимости, трудно оценить объективно ввиду недостаточного количества уже имеющихся знаний, и, в связи с этим, вероятнее обесценить [7. C. 117].

Касаясь психолого-педагогических факторов, Е.И. Машбиц называет три группы задач, решаемых в ходе компьютеризации обучения:
1. Теоретическое аргументирование необходимости компьютеризации учебного процесса;

2. Создание связей между практическими педагогическими алгоритмами и технологическими возможностями компьютерного обучения;

3. Разработка программных продуктов и интегрирование их в учебный процесс [3. С.22].

Для российского и мирового образования выпускник является не просто специалистом с необходимым количеством профессиональных навыков для решения ежедневных задач, но и человеком с собственной общественной позицией, которую он может мотивировать и аргументировать, обладающий устойчивой психикой, толерантный, настроенный на продуктивность в собственной деятельности, самоорганизованный, способный управлять собственной жизнью и находиться в системе ценностей современного цивилизованного мира. Во время обучения в вузе важно достаточное время уделять формированию нравственной парадигмы будущих специалистов, способствовать воспитанию открытых личностей, чья жизнь будет насыщенной и продуктивной. Необходимо поддерживать стремление обучающихся к саморазвитию, поскольку оно положительно влияет на культурное и духовное развитие личности. Решая эти задачи при помощи классических методов обучения, можно помочь студентам приобрести ценности и моральные установки, которые помогут в дальнейшей жизни принимать адекватные и оправданные решения [2. С. 32].

Таким образом, учитывая исследования современных авторов, можно отметить фундаментальную важность изменения адаптации человека в новой информационной среде. Особенности этой среды стимулируют корректировки существующих механизмов социокультурного и природного развития человека, а также способствуют выработке новых. Становясь стержнем цивилизации, современные инфотехнологии способны изменить жизнь человека, ее качество и особенно - содержание [4. С.38].

ЛИТЕРАТУРА

1. Борисенко А.В. Сущность процесса социокультурной адаптации и идентификации человека в информационном пространстве// Журнал научных публикаций аспирантов и докторантов. 2014. № 7 (97). С. 59-63.

2. Волкова Н.П. Традиционные и инновационные технологии современного образования//Философское образование. 2016. № 1 (33). С. 32-36.

3. Грибан 0.Н. Формирование информационной компетентности студентов педагогического вуза: монография / ФГБоУ ВПо «Урал. гос. пед. ун-Т». - Екатеринбург: Урал. гос. пед. ун-т, 2015. - 162 с.

4. Информационная эпоха: вызовы человеку/монография. Отв. ред. И.Ю. Алексеева, А.Ю. Сидоров - М.: РОССПЭН, 2010.

5. Калимуллин Д.Д. Проблема адаптации человека в социокультурном информационном пространстве //Вестник Казанского государственного университета культуры и искусств. - Казань, из-во: Казанский государственный университет культуры и искусств, 2007. С. 255-258.

6. Капустина Д.М. Оценка использования современных компьютерных технологий в преподавании в высшей школе//Философское образование. 2016. № 1 (33). С. 36-40.

7. Капустина Д.М. Проблема адаптации человека в информационном пространстве//Философское образование. 2017. № 1 (35). С. $117-121$. 
8. Лунькова Е.Ю. Возможности использования информационно-образовательного пространства в обучении студентов-психологов // Культура и образование. - Сентябрь 2013. - № 1. [Электронный ресурc]. URL: http://vestnik-rzi.ru/2013/09/822 (дата обращения: 19.11.2013).

9. Несмелова Н.Н. Адаптация человека в информационной среде: индивидуальные особенности и механизмы/ Материалы XII международной научнопрактической конференции. Наука. Информатизация. Технологии. Образование. 2019.C 178-185.

10. Переслегин А.Г. Проблемы информатизации образовательного процесса// МГтУ ГА.2018. № 1.Т. 3.С.43-48.

11. Сунгурова Н.Л. Психологическое отношение студентов к информационно-компьютерным обучающим средам // Вестник РУДН. Серия: Психология и педагогика. 2013. №3. С.116-122.

12. Токтарова В.И., Федорова С.Н. Адаптация студентов к обучению в условиях электронной информационно-образовательной среды вуза // Вестник Марийского государственного университета. 2019. №3 (35). С. 383-390.

(c) Волкова Нина Петровна (petrovnavolkova@mail.ru).

Журнал «Современная наука: актуальные проблемы теории и практики»

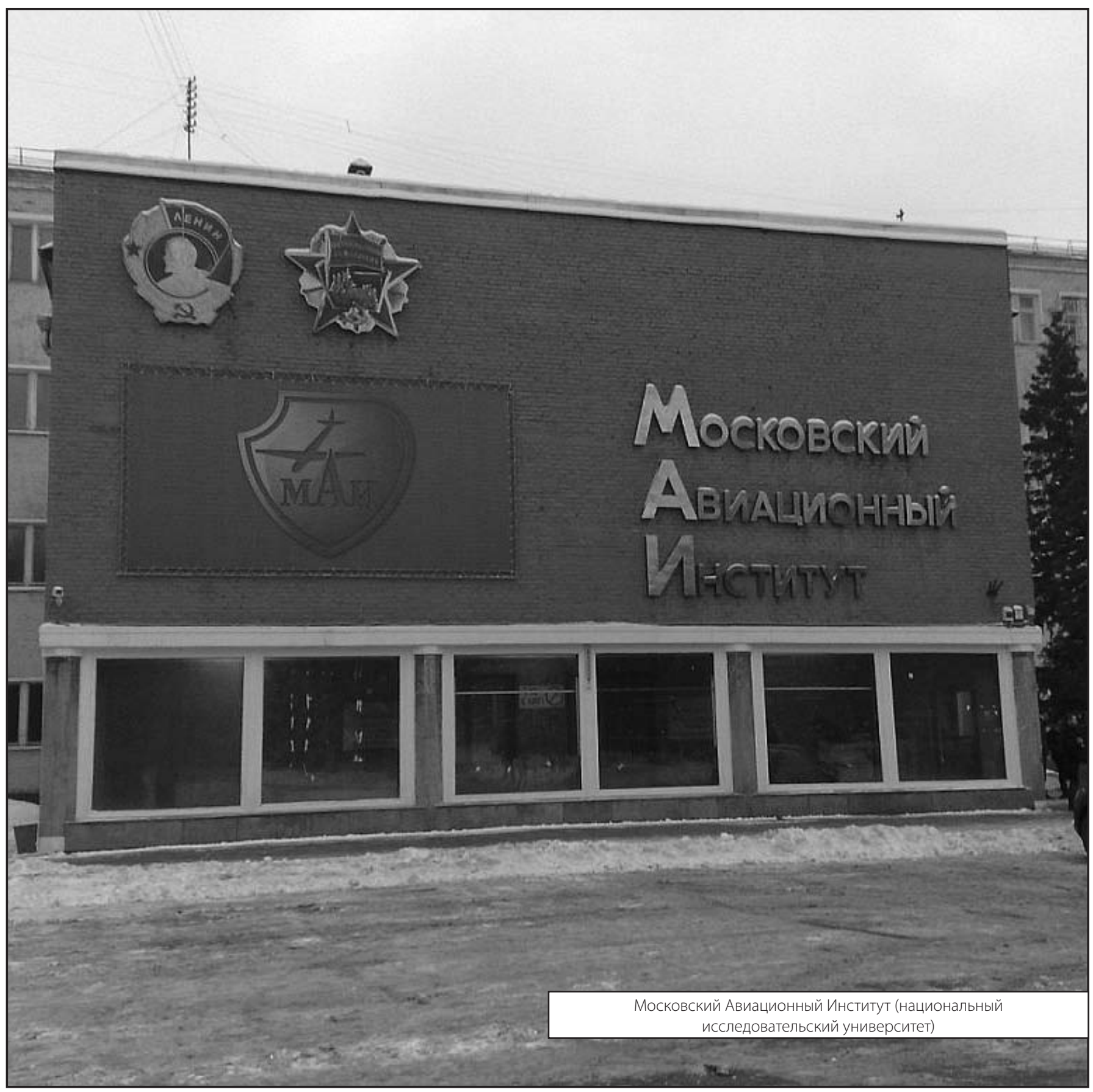

